\title{
Determinants of biosecurity utilisation among small scale broiler farmers in Ekiti
} State, Nigeria

'Oluwasusi J. O. 'Nwosu K. R. ${ }^{3}$ Olajuyigbe, B. F.

1.2. Department of Biological Sciences, Afe Babalola University, Ado-Ekiti (ABUAD), P.M.B 5454, Ado-Ekiti, Ekiti State. Nigeria

${ }^{3}$ Department of Animal Science, University of Ibadan, Ibadan, Nigeria

Corresponding author: yesky20@yahoo.com,

Abstract

johnkayod@gmail.com(08032094612)

Predictors of biosecurity utilization among broiler farmers are of concern on the need for guaranteed safe meat supply to consumers, guarding against epidemics and sustainability of profitable poultry enterprise. Therefore, this study looked into the determinants of biosecurity utilization among broiler farmers in Ekiti State. Multistage and random sampling techniques were used to select 135 respondents for the study; data were collected using structured interview schedule, frequency counts, percentages, PPMC and linear regression. Majority (60.7\%) of the respondents was males, young (31-40years), moir than half $(51.1 \%$ and $53.3 \%$ ) were married and had poultry as their primary occupation. Majority $(67.4 \%$ and 65.9\%) always sourced information on biosecurity practices from friends and had high level of biosecurity awareness. Non-compliance of visitors with parking of cars away fiom the poultry house was rated as a very serious constraint to biosecurity utilization. Level of education $(\beta=0.621)$, poultry experience $(\beta=0.416)$, membership of organization $(\beta=0.511)$, income level $(\beta=0.401)$, awareness of biosecurity $(\beta=0.317)$ and constraints to biosecurity utilization $(\beta=0.266)$ were contributors to utilization of biosecurity for broiler production. Hence, further information on biosecurity practices for broiler production and how the respondents can market their broilers effectively should be provided by public extension agents and channeled through poultry association.

Keywords: Utilization, Broiler farmers, Determinants, Biosecurity, Awareness

\section{Introduction}

Poultry is fast becoming an important source of income and employment to poultry operators, likewise a sustainable source of protein to consumers in Nigeria. It is not restricted by any culture or tradition. Poultry is a contributor to both rural and urban livelihoods, it posits enhancement of households income and protein adequacy in diets. Poultry production as an aspect of livestock production is important to the biological needs, economic and social development of the people in any nation (Oladebo and Ambi-lamdi, 2007). Poultry production is one of the most promising sources of additional income to family earnings, increase household protein intake and quick return from micro level investment in Nigeria (Amos, 2006).

Developing the poultry industry of Nigeria offers a fast means of bridging the protein deficiency that may possibly confront many poor and illiterate homes in the country. Moreover, the importance of poultry to national economy cannot be over emphasized as it has become popular for the small holders that contribute to the economy of the country (Oloogbon and Ambali, 2012). Poultry meat and eggs offer considerable potential for meeting basic animal protein requirement for humans (Folorunsho and Onibi, 2005). The poultry industry has a diversity of income potentials ranging from egg production, 


\section{Determinants of biosecurity utilisation among small scale broiler farmers in Ekiti State, Nigeria}

broiler production, hatchery for day old chicks and poultry equipment. These various poultry sections provide employment and entrepreneurial opportunities to citizenry as life surviving mechanisms. Intensive poultry system remains the major system of enhancing the maximum potential of the poultry business, translating to worthy farm income from commercial poultry production to the poultry operators. However, intensive poultry production poses ambience for the concentration and transmission of pathogens among reared birds. Broiler production seems more practiced among the poultry farmers, plausibly to its quick return on investment between a short period of six to eight weeks. However, broiler production is widely practiced with deep litter system, basically breeding more poultry waste gases such as methane, nitrous oxide and ammonia among others, polluting the air and could cause respiratory diseases among birds flock, inhabiting large microbes easily and allow the spread of diseases as zoonosis and epidemics if not promptly and routinely cleaned by the broiler farmers. The crowding of thousands of birds in an enclosed warm and dusty environment is highly conducive for the transmission of contagious diseases (Collins, 2007). Furthermore, the spread of highly pathogenic avian influenza, other viral, fungal and parasitic infectious diseases that ravage poultry business, posing serious threats to poultry farmers, with potentials of high record of mortality of birds and huge loss of money invested may likely push many poultry farmers to less livelihood sustainable activities.

Biosecurity principles offer procedures and practices which when applied, have great potentials of preventing the entry and exit of disease agents in a farm premises. The high susceptibility of poultry to disease outbreaks makes a comprehensive biosecurity technology a necessary practice in poultry farms to protect the farms from both intentional and unintentional threats from biological agents (Ajewole, 2014a). Research has been carried out to assess the efficiency of biosecurity practices carried among small scale poultry farmers in Nigeria, with results showing reduction of disease causing agents' ability to transmit and spread diseases to poultry when biosecurity is undertaken (Halifia, 2008; Ajewole, 2014b). However, there is dearth information on the determinants of biosecurity practices among small scale broiler farmers who may largely be less enlightened and non-conversant with relevant biosecurity measures that could lead to optimum production and profitable broiler farming.

Hence, constraints like predation, high incidence of diseases, non-guaranteed disease free day-old chicks, poor veterinary services and non-effective medication may not be free from the small scale broiler farmers. It is against this backdrop that this research will help fill this gap and provide answers to the following research questions.

1. Determine the personal characteristics of the broiler farmers,

2. Ascertain the level of awareness of the broiler farmers on biosecurity practices,

3. Identify the extent of utilization of selected biosecurity practices among the broiler farmers; and

4. Investigate the constraints faced by respondents in utilizing the biosecurity practices to improve their broiler production.

The hypotheses were stated in the null form (Ho) 


\section{Oluwasusi, Nwosu and Olajuyigbe}

$\mathrm{H}_{0} \mathrm{l}$ : There is no significant relationship between the awareness level of broiler farmers and their level of utilization of biosecurity practices.

$\mathrm{H}_{0} 2$. There is no significant relationship between the constraints encountered by the poultry farmers in utilizing biosecurity practices and their level of utilization of biosecurity practices.

$\mathrm{H}_{0} 3$ : There is no significant contribution of personal characteristics, awareness of biosecurity practices and constraints faced by small scale broiler farmers in utilizing biosecurity practices to their utilization of biosecurity practices.

\section{Methodology}

The study was carried out in Ekiti State, South West, Nigeria with the capital at ADO-Ekiti. Majority of the residents of Ekiti state engage mainly in subsistence agriculture as a primary means of livelihood, poultry and artisanship are among many secondary means of livelihood of the people. The population of the study comprised of all poultry farmers registered with the poultry farmers association of Ekiti State. A multistage sampling procedure was used to select respondents for this study. Two (2) of the three (3) senatorial zones (Ekiti South and Ekiti North) representing $66.7 \%$ of the total senatorial districts were selected using random sampling technique. In each of the selected zones, $50 \%$ of the senatorial zones having five towns each were selected using random sampling technique to give three towns each from the senatorial districts. Ekiti South (Ado, Efon and Ikogosi) and Ekiti North (Oye, Otun and Ikole). A list of poultry farmers was obtained from each of the senatorial zones ( 340 from Ekiti South and 334 from Ekiti North), while 20\% of them were selected to give a total of 135 poultry farmers (68 poultry farmers from Ekiti South and 67 poultry farmers from the
Ekiti North). Structured questionnaire containing open and close, ended questions was used to collect the data for this study. Respondents indicated their sources of information on biosecurity practices from a list of biosecurity practices for broiler production on a two point scale of yes (1) and no $(0)$ with frequency of accessibility of always (2), occasionally (1) and never (0). Frequency counts and percentages were used to summarize the data. Respondents' awareness of biosecurity practices was measured by asking them to respond to a list of awareness statements freely. Respondents who answered correctly were awarded score of leand wrong answers were scored 0 . A mean score was obtained for awareness based on the scale. Respondents who scored below the mean value had low level of awareness, while those whose awareness score equals or greater than the mean had a high level of awareness. Respondents reacted to the listed constraints on a three-point scale of "severe constraint", "mild constraint" and "not a constraint", scores of 2,1 , and 0 were awarded to them respectively. The frequency and percentage of each constraint was calculated and this was used to rank them, so that the highest percentage score means the most severe constraints. Utilization of biosecurity practices was operationalized in terms of extent to which broiler farmers engage the use of selected biosecurity measures on a three point scale of always (2), occasionally (1) and never (0).

Table 1 reveals that majority $(60.7 \%)$ of the respondents were males, more than half $(51.1 \%)$ were married and $33.3 \%$ of the respondents were in the age category of 31 40 years. This implies that broiler farming was more practiced by youthful male and married respondents of the population. This may be as a response to more demanding family and social responsibilities on the 


\section{Determinants of biosecurity utilisation among small scale broiler farmers in Ekiti State, Nigeria}

male population than the females, as venturesome tenet for economic coping strategy. This result agrees with Yinusa (1999) that the youth population is innovative, motivated and adaptable individuals. Also, large proportion of the respondents $(83 \%)$ had a form of formal education. The implication is that majority of the respondents stand the chance of accessing information on profitable broiler production from array of sources. About $(38.5 \%)$ had a flock size of 1001 to 5000 while few $(6.7 \%)$ of the respondents had a flock size of above 10,000 broilers. This implies that the broiler farmers were practicing at small scale level as entrepreneurial drive for employment creation and security in the face of absence white collar jobs in the country.

The analysis showed that all (100\%) of the respondents belonged to poultry association while $(52.6 \%)$ belonged to cooperative society. This indicates that poultry association and cooperative society remained respondents' support base of access to reliable birds to stock, vaccines, capital base and relevant information for profitable broiler enterprise. The primary occupation of the respondents showed that more than half $(53.3 \%)$ had poultry as their primary occupation while $(46.7 \%)$ had civil service, farming and artisanship as secondary occupations. This showed that many of the broiler farmers were involved in broiler production to diversify their income, strengthen their income base and served as an additional stream of income to them. This result is in consonance with Sani et al (2000) that poultry can be established with minimum capital and as a side project. The result showed that Christians $(52.6 \%)$ dominated the broiler enterprise while
Muslims (39.3\%) and traditionalists (8.1\%) were represented among the broiler farmers. This implies that no religion group forbids broiler production.

Barely half $(48.9 \%)$ of the respondents made a monthly income of ? 20,001 to ? 29,000 from broiler enterprise. This may be due to the little capital invested into the broiler business, as close to half of the broiler farmers had other income generating revenues. This result agrees with Akanni (2007) who stated that low income from poultry business is one of the constraints to increased productions faced by small scale poultry farmers.

Various information sources on biosecurity practices for poultry production are explored by the broiler farmers to improve their knowledge. The result on Table 2, revealed that majority $(67.4 \%)$ of the respondents' access information on biosecurity measures always for broiler production from association and relationship with friends. This implies that information was gotten more informally by broiler farmers than from formal mass media and extension agents. More than half $(58.5 \%)$ of respondents also obtained information on biosecurity measures always for broiler production through poultry association. This implies that broiler farmers were willing to seek and utilize any information on biosecurity measures that will increase their broiler production. Furthermore, this could be to the a priori belief that right targeting of potential adopters of innovation as a group offers development of model farmers which bring about a multiplier effect of innovation dissemination on developed and evolving innovations for better practices in all farming activities by communication experts. 
Oluwasusi, Nwosu and Olajuyigbe

Table 1: Distribution of respondents by personal characteristics

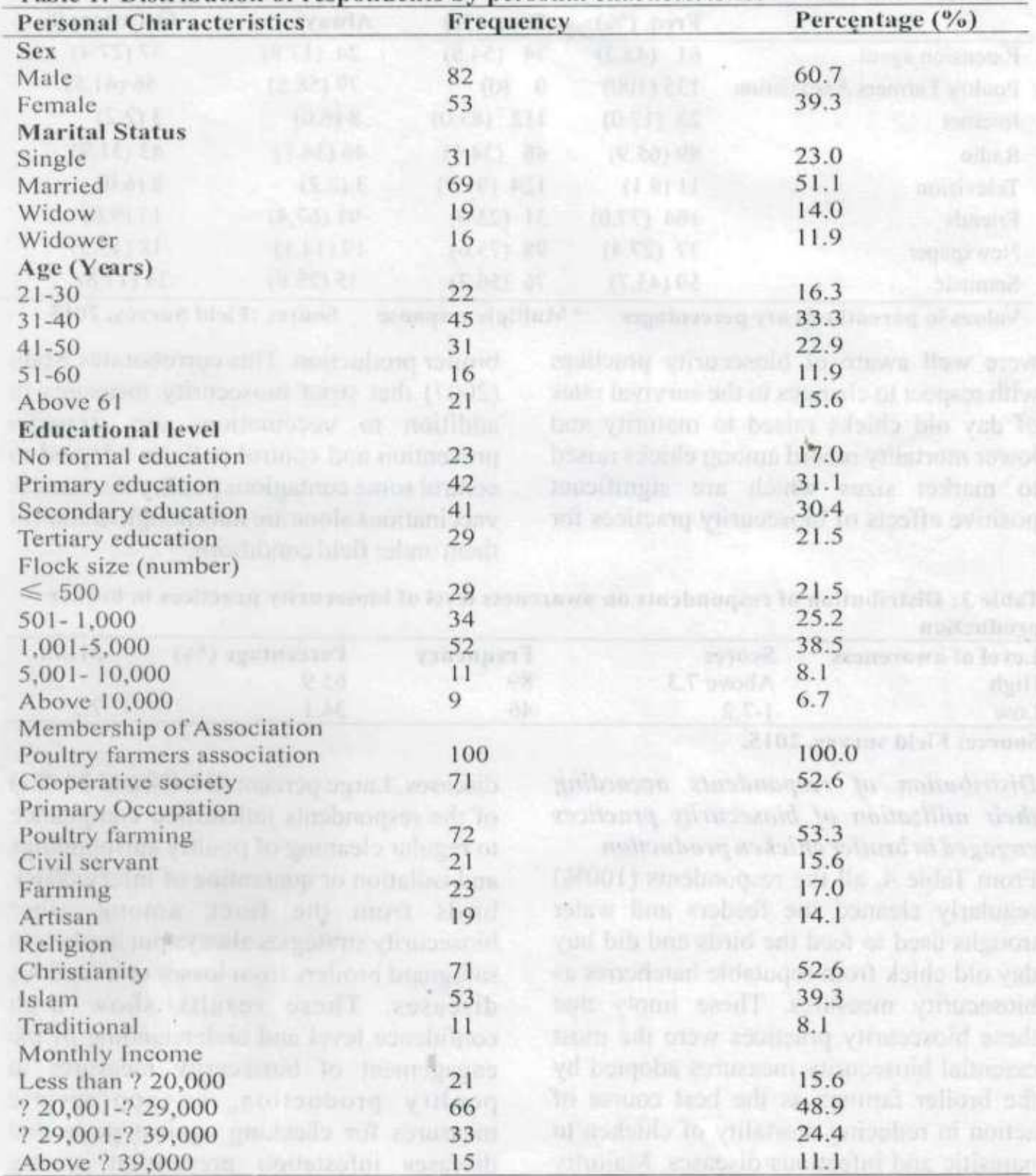

Source: Field Survey, 2015

Broiler Chicken Farmers' level of awareness on Biosecurity Measures

From Table 3, the mean score of the respondents on awareness of biosecurity measures for broiler production was obtained as 7.3 and categorized on the basis of high level of awareness (above 7.3) and low level of awareness (below 7.3). The result showed that majority $(65.9 \%)$ had scores above the mean, hence were highly aware of biosecurity measures for broiler production while few $(34.1 \%)$ had low awareness of biosecurity practices. This depicts that broiler farmers in the study area 
Determinants of biosecurity utilisation among small scale broiler farmers in Ekiti State, Nigeria Table 2: Distribution of respondents' sources of information on biosecurity practices

\begin{tabular}{llllc}
\hline Sources of Information & Yes & No & \multicolumn{2}{l}{ Frequency of accessibility } \\
& Freq. (\%) & Freq. (\%) & Always & Occasionally \\
\hline Extension agent & $61(45.2)$ & $74(54.8)$ & $24(17.8)$ & $37(27.4)$ \\
Poultry Farmers Association & $135(100)$ & $0(0)$ & $79(58.5)$ & $56(41.5)$ \\
Internet & $23(17.0)$ & $112(83.0)$ & $8(6.0)$ & $3(2.2)$ \\
Radio & $89(65.9)$ & $46(34.1)$ & $46(34.1)$ & $43(31.9)$ \\
Television & $11(8.1)$ & $124(91.9)$ & $3(2.2)$ & $8(6.0)$ \\
Friends & $104(77.0)$ & $31(23.0)$ & $91(67.4)$ & $13(9.6)$ \\
Newspaper & $37(27.4)$ & $98(75.6)$ & $19(14.1)$ & $18(13.3)$ \\
Seminar & $59(43.7)$ & $76(56.3)$ & $35(25.9)$ & $24(17.8)$
\end{tabular}

Values in parenthesis are percentages

* Multiple response

Source :Field Survey, 2015

were well aware of biosecurity practices with respect to changes in the survival rates of day old chicks raised to maturity and lower mortality record among chicks raised to market sizes which are significant positive effects of biosecurity practices for broiler production. This corroborates Abdu (2007) that strict biosecurity measures in addition to vaccinations are strategic prevention and control policies adopted to control some contagious poultry diseases as vaccinations alone are not enough to control them under field conditions.

Table 3: Distribution of respondents on awareness level of biosecurity practices in broiler production

\begin{tabular}{lllll}
\hline Level of awareness & Scores & Frequency & Percentage (\%) & Mean \\
High & Above 7.3 & 89 & 65.9 & \\
Low & $1-7.2$ & 46 & 34.1 & 7.3 \\
\hline
\end{tabular}

Source: Field survey, 2015.

Distribution of respondents according their utilization of biosecurity practices engaged in broiler chicken production

From Table 4, all the respondents (100\%) regularly cleaned the feeders and water troughs used to feed the birds and did buy day old chick from reputable hatcheries as biosecurity measures. These imply that these biosecurity practices were the most essential biosecurity measures adopted by the broiler farmers as the best course of action in reducing mortality of chicken to parasitic and infectious diseases. Majority $(89.6 \%$ and $88.1 \%)$ of the respondents respectively indicated that packing of litters on regular basis and regular vaccination of stocked birds were biosecurity measures always adopted to prevent mortality losses of their broilers to parasitic and infectious diseases. Large percent ( $84.4 \%$ and $84.4 \%$ ) of the respondents indentified compliance to regular cleaning of poultry surroundings and isolation or quarantine of infected/sick birds from the flock among other biosecurity strategies always put in place to safeguard broilers from losses to infectious diseases. These results show high confidence level and understanding of the engagement of biosecurity measures in poultry production, as appropriate measures for checking against pests and diseases infestation prevention among broiler farmers in the study area. Hence, biosecurity measures were well adopted and utilized among the broiler farmers possibly, because they were proven efficient for profitable broiler production. 
Table 4: Distribution of respondents on utilization of biosecurity practices for broiler production

\section{Utilization of Biosecurity Practices}

\section{Always}

Frequency

$(\%)$

Regular cleaning of feeders and water troughs

Packing of litters on regular basis

Regular Vaccination of stocked birds

Fencing of poultry house

Regular cleaning of poultry surroundings

Avoiding overcrowding of birds

Dipping of foot on mat soaked with disinfectant before

entering poultry pen

Buying of day old chick from reputable hatcheries

protecting their chicks and birds from diseases and pests.

Isolation or quarantine of infected/sick birds

Burying / Burning of dead birds

Restriction of visitors into the pen house
$135(100)$

$121(89.6)$

$119(88.1)$

$89 \quad(65.9)$

$114(84.4)$

$98 \quad(75.6)$

$102(75.6)$

$135(100)$

$114(84.4)$

$114(84.4)$

$0 \quad(0)$

Frequency of Use

Values in parenthesis are percentages

${ }^{*}$ Multiple response

Occasionally Never

Freq $(\%)$

Freq (\%)

$0(0)$

$0(0)$

$14(10.4)$

$16(11.9)$

$0(0)$

$0(0)$

$0(0)$

$21(15.6)$

$46(4.1)$

$37(27.4)$

$0(0)$

$.0(0)$

$33(24.4)$

$0(0)$

$0 \quad(0)$

$0(0)$

Table 5 showed the level of utilization of biosecurity practices among broiler farmers with a large percent $(65.9 \%)$ having a high level of utilization while less than half $(34.1 \%)$ had a low utilization level of

biosecurity practices for broiler production. This implies that many of the broiler farmers engaged in the use of biosecurity practices for their broiler production to its effective and efficient nature of reducing mortality record.

Table 5: Distribution of Respondents on the level of utilization of biosecurity practices

\begin{tabular}{lllllll}
\hline Level of utilization & Scores & Frequency & Percentage (\%) & Max & Min & Mean \\
\hline High & $38.3-127$ & 89 & 65.9 & 127.0 & 18.2 & 38.3 \\
Low & $18.2-38.2$ & 46 & 34.1 & & & \\
\hline
\end{tabular}

Table 6 showed the various constraints encountered by broiler farmers in complying with biosecurity practices for poultry production. According to the result, majority $(75.6 \%$ and $72.6 \%)$ considered non-compliance of visitors with parking of cars away from the poultry house, high cost of providing protective cloth and boot to workers and visitors, respectively. Lack of adequate fund $(71.1 \%)$ was very severe constraint to utilizing biosecurity practices for broiler production. Large percent $(64.4 \%)$ saw poor market and broiler selling price as severe constraint to upholding biosecurity practices for broiler production. A total of $(54.8 \%$ and $52.6 \%)$ of the respondents considered poor extension services and high cost of poultry equipment

respectively as very severe constraints to engaging biosecurity practices in broiler production. These imply that maintenance of traffic flow of vehicle and human flow could not be well checked, likewise lack of adequate funding were the most serious constraints confronted by the broiler farmers among other constraints. This result agrees with Cardona, et al (2007) that impediments to the actualizing of the three principles of biosecurity practices involve isolation of poultry premises from sources of infection, controlling of traffic flow in and out of susceptible poultry area through fencing, gates, human and vehicle controls within the farm and into the farm and sanitation of equipment, housing and offer of protective clothing for poultry workers and visitors. 
Determinants of biosecurity utilisation among small scale broiler farmers in Ekiti State, Nigeria Table 6: Distribution of Broiler Farmers according to constraints encountered in Biosecurity Practices Utilization

\begin{tabular}{llll}
\hline Constraints & Very Severe (\%) & Severe (\%) & Not Severe (\%) \\
\hline Poor extension services & 54.8 & 45.2 & 0.0 \\
High cost of vaccines and feed & 38.5 & 59.3 & 2.2 \\
High cost of poultry equipment & 52.6 & 47.4 & 0.0 \\
Poor knowledge on correct stocking size & 23.0 & 17.0 & 60.0 \\
Theft & 14.1 & 3.7 & 82.2 \\
Poor market and broiler selling price & 35.6 & 64.4 & 0.0 \\
Lack of adequate fund & 71.1 & 28.9 & 0.0 \\
High cost of disinfectants in the footbaths & 16.3 & 18.5 & 65.2 \\
High cost of providing protective cloth and booth & 72.6 & 27.4 & 0.0 \\
to workers and visitors & & & \\
Non-compliance of visitors with parking of cars at & 75.6 & 24.4 & 0.0 \\
a distance to the poultry house & & & \\
\hline
\end{tabular}

Source: Field survey, 2015

\section{Hypotheses Testing}

The following hypotheses were stated in the null form and tested.

Hypothesis 1: There is no significant relationship between the awareness of broiler farmers on biosecurity practices and their utilization of biosecurity practices.

Table 7 showed the correlation value of 0.461 and $P$-value of 0.002 , indicating that there is a significant relationship between

respondents' level of awareness of biosecurity practices and their level of utilization of biosecurity practices. Therefore, the null hypothesis is rejected. This implies that respondents' awareness level of biosecurity practices has a positive effect on their level of biosecurity utilization. Herrara (2004) agreed with this finding that biosecurity measures which include cleaning and disinfection in the poultry industry, are critical to the production process and the efficacy of the disinfectants used.

Table 7: Relationship Between Respondents' Awareness of Biosecurity Practices and their Level of Biosecurity Practices Utilization

\begin{tabular}{|c|c|c|}
\hline Variable & r-value & p-value \\
\hline Respondents ${ }^{\prime}$ awareness and utilization of biosecurity practices & 0.461 & $0.002^{*}$ \\
\hline
\end{tabular}

Hypothesis 1: There is no significant relationship between constraints faced by respondents in the utilization of biosecurity practices and their level of utilization of biosecurity practices

Table 8 showed the correlation value of 0.171 and $P$-value of 0.002 , indicating that there is a significant relationship between the constraints faced by broiler farmers in using biosecurity and their level of utilization. Therefore, the null hypothesis is rejected. This implies that the constraints faced by the broiler farmers in utilizing biosecurity for production could hinder their effective and efficient biosecurity adoption, despite its tested and proven benefits to the broiler farmers. This could adversely affect broiler farmers' optimization of biosecurity potential and benefits of utilization over other methods of broiler production. 
Table 8: Relationship Between Constraints Faced by Respondents in Utilizing Biosecurity Practices and their Level of Utilization of Biosecurity Practices

\begin{tabular}{lll}
\hline Variable & r-value & p-value \\
Constraints to use of Biosecurity & 0.171 & $0.002 *$ \\
\hline * Correlation is significant at 0.05 & &
\end{tabular}

Linear Regression Estimation on Factors Determining Broiler Farmers' Utilization of Biosecurity Practices

The result of the analysis shown in Table 9 indicates that broiler farmers utilization of biosecurity was significant with regard to level of education $(\beta=0.621 ; p=0.001)$. The regression coefficient for biosecurity utilization and poultry experience was likewise significant $(\beta=0.416 ; p=0.012)$. Biosecurity utilization among respondents was also significantly influenced by the membership of organization $(\beta=0.511$; $\mathrm{p}=0.003$ ). Income level of broiler farmers ICTs $(\beta=0.401 ; p=0.002)$ and awareness of biosecurity $(\beta=0.317 ; p=0.001)$ were significant contributors to biosecurity utilization by the broiler farmers. Constraints faced by respondents' in utilizing biosecurity measures for broiler production $(\beta=0.266 ; p=0.000)$ was a significant contributor to biosecurity utilization. The $\mathrm{R}$-square value for all significant variables was 0.751 , which means that these variables accounted for $75.1 \%$ of the variation in broiler farmers' level of biosecurity utilization. This implies that awareness of biosecurity practices, years of poultry experience, income level, constraints to utilizing biosecurity practices and educational level of the broiler farmers were contributory factors to the adoption and use of biosecurity practices among the broiler farmers. This finding is corroborated by Nwaru (2007) who reported that education and training help to unlock the natural talents and inherent enterprising qualities of people, enhances their abilities to understand and evaluate productive techniques leading to increased productivity and income.

Table 9: Regression Analysis of Selected personal characteristics, awareness on biosecurity practices, constraints to utilization of biosecurity practices and utilization of biosecurity practices

\begin{tabular}{lllll} 
Variables & Beta Value & t-value & P-value & Decision \\
\hline Constant & & 25.0614 & 0.000 & Significant \\
Sex & 0.029 & 0.617 & 0.662 & Not Significant \\
Age & 0.009 & 0.007 & 0.372 & Not Significant \\
Religion & -0.030 & -1.194 & -0.318 & Not Significant \\
Marital Status & -0.080 & -1.701 & -0.251 & Not Significant \\
Level of education & 0.621 & 18.134 & 0.001 & Significant \\
Poultry experience & 0.416 & 17.633 & 0.012 & Significant \\
Membership of organization & 0.511 & 14.111 & 0.003 & Significant \\
Income level & 0.401 & 9.712 & 0.002 & Significant \\
Awareness of Biosecurity & 0.317 & 11.611 & 0.001 & Significant \\
Constraints to Biosecurity Utilization & 0.266 & 10.217 & 0.000 & Significant \\
\hline
\end{tabular}

$\mathrm{R}=0.871, \mathrm{R}$-square $=0.751$, Adjusted $\mathrm{R}$-square $=0.723, \mathrm{df}=10, \mathrm{~F}=59.218$

\section{Conclusion}

The study established that majority $(60.7 \%)$ of the broiler farmers were males and belonged to the age category of 31-40years, while $(38.3 \%)$ had a flock size of 10015000 broilers. They all belonged to poultry farmers association, more than half $(51.1 \%$ and $53.3 \%$ ) respectively were married and 
had poultry as their primary occupation, with both Christians and Muslims as key players in biosecurity practices for broiler production. Majority (67.4\%) always sourced information on biosecurity practices from friends, had high level of awareness $(65.9 \%)$ and high level of utilization of biosecurity practices $(65.9 \%)$. The most prevalent constraint among the broiler farmers was non-compliance of visitors with parking of cars at a distance to poultry house. The study also concluded that there was a significant relationship between respondents' level of awareness on biosecurity practices and their level of biosecurity utilization. In the same vein, there was a significant relationship between the constraints faced by the broiler farmers in utilizing biosecurity practices and their level of biosecurity utilization. The crucial factors in determining utilization of biosecurity practices for broiler production were level of education, poultry experience, membership of organization, income level, awareness of biosecurity and constraints to biosecurity utilization among the broiler farmers in the study area. In light of these conclusions, the following recommendations are hereby made:

(1) In order to improve the utilization of biosecurity practices for broiler production, total compliance of visitors as well as poultry workers must be ensured by the broiler farmers to biosecurity principles of isolation of sick birds from healthy ones, disinfection and sanitation of the poultry house and equipment regularly, likewise control of traffic in the poultry farm through maintenance of cars being parked at some distance away from the poultry farm.

(2) Policies to make loans as formal credits accessible by the government to poultry farmers through duly registered poultry farmers association should be well implemented with sustainability measures, as capital is important to ensure biosecurity practices as a boost to the profitability and expansion of the broiler production enterprise.

(3) Government should focus on how to solve the constraints of poor extension services and poor market for broilers. This can be done through proper monitoring of the extension officers and reward the dedicated extension staff of the Agricultural Development Programme adequately through improved welfare packages. In the same vein broiler farmers should be encouraged to pay for advertisement of their broilers and processed meat, sales period and prices of the broilers at affordable fees on the State radio and television to members of the public.

(4) Government should increase the awareness and sensitization of the broiler farmers on biosecurity practices through more frequent visits of extension officers to poultry farmers association that offers a great platform to interact with the broiler farmers, disseminate profitable biosecurity practices to the farmers and offer appropriate marketing information to the broiler farmers.

\section{References}

Abdu, P. A. 2007. Manual of Important Poultry Diseases in Nigeria (2nd edition). MacChinMultimedia Designers, Samaru-Zaria. Pp 1 100. 
Akanni, I. A. 2007. "Effect of microFinance on Small Scale Poultry business in South WesternNigeria" Emirate Journal of Food and Agriculture. 19(2): 38-47 Accessed on March 23,, 2016 a $t$ http://www.cfa.uaeu.ac.ae

Amos, T. T. 2006. Analysis of Backyard poultry production in Ondo State, Nigeria. International Journal of Poultry Science. 5(3): 247-250.

Cardona, C., David, A. B, Daniel, D. A, Beltrain-Alcrudo, D., Walter, M. B., Halvorson, D. A., Hudson, W. T., Sandrock, C., Clifford, D. and Shanks, S 2007. Avian Flu School Course Guide, Module 4. The Regents of the University of California, Davis Campus.

Collins, M. L 2007. The role of intensive poultry production industry in the spread of avianinfluenza Accessed $28^{\text {th }}$ May, 2015 from http://www.cwf.org.uk/includes/d ocuments $/ \mathrm{cm}$ docs $/ 2008$.

Folorunsho, O. R. and Onibi, G. E. 2005. Assessment of the Nutritional Quality of Eviscerated Waste from Selected Chicken Types. In Onibi, G.E., Agele, S.O. and Adekunle, V.A.J. (eds). 2005. Proceedings of the Ist Annual Conference on Developments in Agriculture and Biological Sciences. 27th April, 2005. School of Agriculture and Agricultural Technology, Federal University of Technology, Akure, Nigeria, pp: 300 .

Halifa, M. 2008. Good biosecurity practices in non integrated c o m m e r i a 1 a n $\mathrm{d} n$ scavengingproduction systems in Tanzania. FAO Study report. Pp 128.
Herrera, A. G. 2004. Nontraditional method of evaluating disinfectants: With isolated microorganisms from the food factory. Methods Molecular Biology, 268: 289-291.

Nwaru, J. C. 2007. Gender and Relative Technical Efficiency in $\mathrm{S}$ mallholder A rable CropProduction in Abia State of Nigeria. International Journal of Agriculture and Rural Development, 10(12): 25-34.

Oladeebo, J. O. and Ambe- lamidi, A. I. 2007. Profitability, Input Elasticity and Economic Efficiency of poultry production among youth farmers in Osun state, Nigeria: International Journal of Poultry Science 6(12):994-998.

Ologbon, O. A. C and Ambali, O. I. 2012. Poultry Enterprise Combination among Small-Scale Farmers in Ogun State, Nigeria: A Technical Efficiency Approach. Journal of Agriculture and Veterinary Science, 4: 7-15.

Sani, R. M., Tahir, I. and Kushwaha, S. 2000. Economics of Poultry Production in Bauchi State: A Case Study of Bauchi Local Government Area. Nigerian Journal of Animal. Production. 27: 09113.

Yinusa. M. B. 1999. North farms alone: A study of rural livelihoods in the middle belt of Nigeria. DARE ASLD working paper 38.

Received: $5^{\text {th }}$ November, 2016 Accepted: $2^{\text {nat }}$ February, 2017 